\title{
INFLUENCE OF CROSSLINKING ON THE SEISMIC PERFORMANCE OF UNBONDED FIBER REINFORCED ELASTOMERIC ISOLATORS (UFREI) MADE OF REGENERATED RUBBER
}

\author{
Gaetano Pianese $^{1}$, Davide Torrini ${ }^{1}$, Gabriele Milani ${ }^{1}$, Antonio Formisano ${ }^{2}$ \\ ${ }^{1}$ Politecnico di Milano \\ Piazza Leonardo da Vinci 32, 20133 Milano, Italy \\ e-mail: gaetano.pianese@polimi.it, davide.torrini@mail.polimi.it, gabriele.milani@polimi.it \\ ${ }^{2}$ School of Polytechnic and Basic Sciences "Federico II" \\ Piazzale Tecchio 80, 80125 Napoli, Italy \\ antonio.formisano@unina.it
}

\begin{abstract}
Recent earthquakes have highlighted the high seismic vulnerability of the structures and the need of retrofitting interventions. Different seismic protection strategies and techniques can be used to increase the seismic capacity of existing masonry constructions. Common retrofitting techniques are generally based on a strengthening approach. Instead, innovative retrofitting strategies can be used to mitigate the effect of earthquakes, with the aim of decreasing the seismic demand on the structure or increasing its energy dissipation capacity. One of the most innovative devices is the Unbonded Fiber Reinforced Elstomeric Isoletors. UFREIs are made of alternate layers of fiber and rubber and they are interposed between the ground and the foundation, with the particularity that no bonding or fastening is provided between the bearing and top-bottom supports. In this paper, through the FE software code Abaqus, a series of nonlinear dynamic analysis are performed to investigate the influence of crosslinking on the seismic performance of UFREI made of regenerated rubber. Numerical results show that the devices vulcanized at $130^{\circ} \mathrm{C}$ for 40 minutes, although having suboptimal crosslinking density, are suitable to properly isolate low-rise buildings.
\end{abstract}

Keywords: Base Isolation, Fiber Reinforced Elastomeric Isolator, Vulcanization, Regenerated Rubber, FE Analysis. 


\section{INTRODUCTION}

The elastomeric isolators are the most used devices to seismically isolate the buildings. Applying the elastomeric isolators can restore the horizontal seismic force and does not cause residual displacements of the isolated building after an earthquake. Usually, they are constituted by several alternating layers of rubber pads and steel interposed by two continuous pads, having the role of limiting vertical deformability. At the same time, they exhibit good deformation capacity in the horizontal direction when subjected to a seismic load. This system isolates the energy transmission of the earthquake from the foundation to the upper structure. Fiber-reinforced elastomeric isolator (FREI) is a new type of elastomeric isolator. Instead of using steel lamina, thin fiber layers are utilized for the vertical reinforcement. FREIs can be applied to the structure in several methods: bonded [1], unbonded [2, 3, 4, 5], partially bonded [6], and friction (no-bonding between rubber and fiber layers). Without steel supports, the isolators can be simply installed between the upper structure and foundation without any bonding or fastening. So, the shear load is transferred through the friction generated between the isolator and the structure surfaces.

A fundamental part of the manufactory process is vulcanization. During this stage, rubber is heated with sulfur or peroxides, accelerators, and activators at around $140-160{ }^{\circ} \mathrm{C}$. This process triggers the formation of crosslinks between long rubber molecules, creating the so called polymer network. Thanks to crosslinks, the chains are prevented from sliding along each other and the rubber becomes elastic. The final mechanical properties of rubber (such as elastic modulus, tensile strength, hardness, etc.) are strongly affected by the degree of curing [7]. Curing temperature and the exposition time are critical parameters to establish to obtain optimal and homogenously distributed mechanical properties of rubber items. This paper investigates the influence of vulcanization on the seismic performance of Unbonded Fiber Reinforced Elastomeric Isolator made of regenerated rubber $[8,9,10]$, considering two types of vulcanization, one at $130^{\circ} \mathrm{C}$ for 40 minutes and one at $150^{\circ} \mathrm{C}$ for 40 minutes.

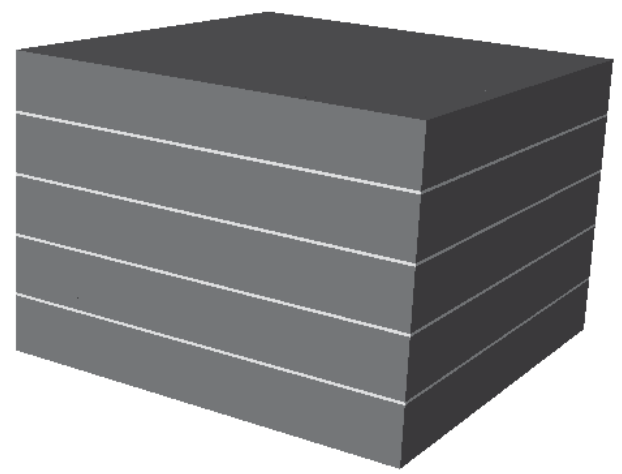

Figure 1: Design of the device object of the study

\section{BASE SEISMIC ISOLATOR}

The device object of the study is constituted by five pads (10 $\mathrm{mm}$ thick) of reactivated EPDM made with $2 / 3$ of regenerated rubber and $1 / 3$ of virgin rubber, and four GFRP lamina $\left(0.5 \mathrm{~mm}\right.$ thick) with a square section of $75 \times 75 \mathrm{~mm}^{2}$ (Figure 1). The results obtained in [11] show that the device cured with a temperature of $130^{\circ}$ for 40 minutes exhibits a non-uniform curing level. So, rubber mechanical properties are non-homogenous within the isolator. On the other hand, the curing temperature of $150^{\circ}$ leads to homogenous curing, with a homogeneous distribution of mechanical properties. To investigate the distribution of curing level for the under-vulcanized device, knife-cuts on the middle vertical and diagonal sections (Figure 2) 
have been done, and the Shore A hardness has been measured with a digital Shore A durometer. As expected, the hardness varies from inner to outer points from values of $48 \pm 2$ Shore A to $60 \pm 2$ Shore A (Figure 2).

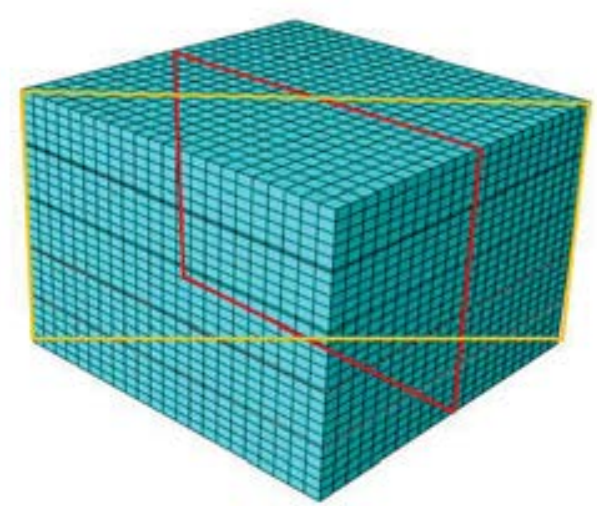

Figure 2: Middle vertical (Red) and diagonal (Yellow) sections for the measurements of the Shore A hardness

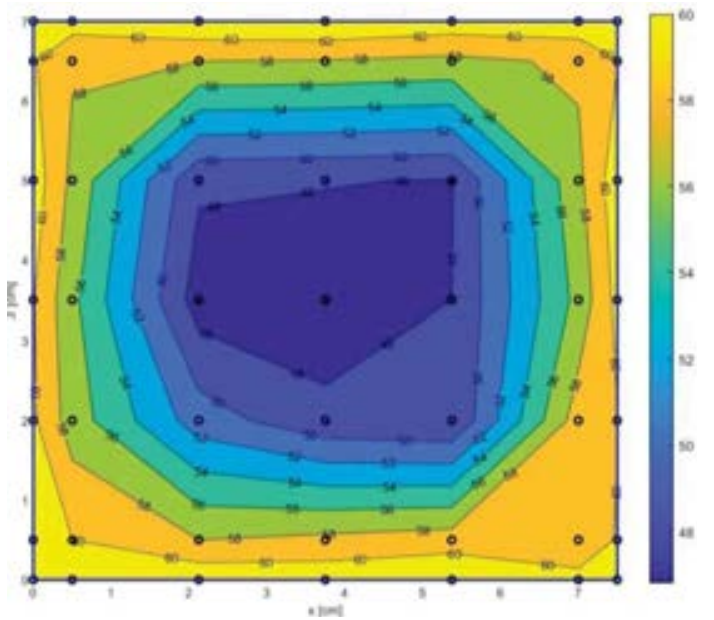

a)

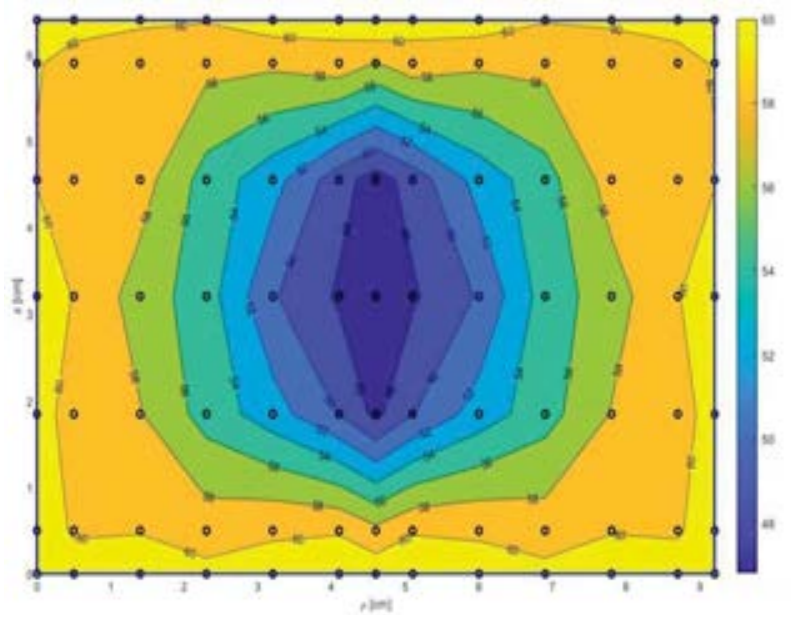

b)

Figure 3: Shore A hardness measured on the middle vertical section (a) and along the diagonal (b) of a device cured at $\mathrm{T}=130^{\circ}$ for 40 minutes

\section{3D FE MODEL - CYCLIC SHEAR ANALYSIS}

In this section, detailed 3D FE analyses are performed on a single UFREI. In particular, the device is subjected to a $0.5 \mathrm{~Hz}$ cyclic horizontal displacement up to $50 \mathrm{~mm}$ (Total rubber height) applied at the top under constant vertical pressure of $2 \mathrm{MPa}$.

Two devices are analyzed. The first one cured at $150^{\circ} \mathrm{C}$ for 40 minutes, with the rubber mechanical properties uniformly distributed, and the second cured at $130^{\circ} \mathrm{C}$ for 40 minutes, with a non-homogeneous distribution of rubber mechanical properties, which vary almost linearly within the isolator in accordance with the results shown in Section 2.

\subsection{D FE Model}

The isolator has been modeled using almost 18000 eight-node brick (C3D8RH) elements with dimensions $3.5 \times 3.5 \times 2 \mathrm{~mm}$. The final mesh is shown in Figure 4. In this study, an unbonded condition has been simulated. There is no bonding between the supports and the rubber pad. For this purpose, a penalty surface-interaction model has been introduced between 
the two surfaces, and a friction coefficient of $\mu=1$ has been applied. On the contrary, a perfect bond using the surface-to-surface tie constraint between rubber and GFRP has been adopted. As visible in Figure 3, rubber mechanical properties on the device cured at $130^{\circ} \mathrm{C}$ linearly changes within the isolator. So, in order to assign different mechanical properties to the model, the EPDM pad has been partitioned into several cubes (Figure 5).

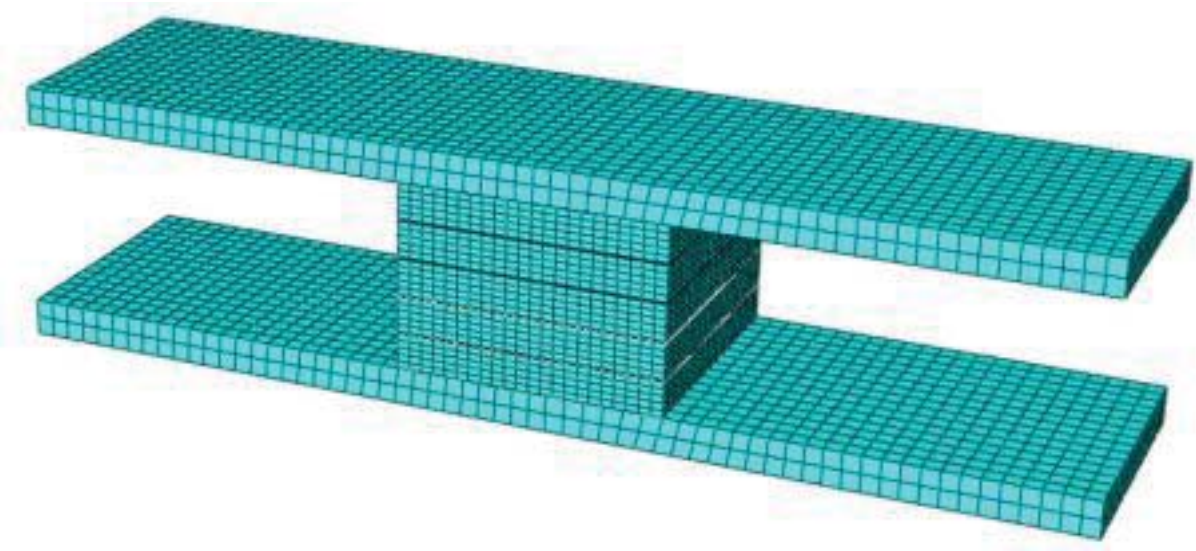

Figure 4: FE model of UFREI75

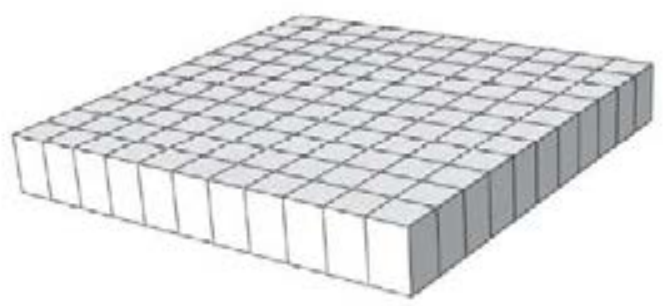

Figure 5: EPDM pad subdivided into several cubes on ABAQUS

Then, three different pads have been considered: middle pad, intermediate pad, and external pad. On each pad, a different distribution of mechanical properties has been assigned as visible in Figure 6 and Figure 7, where the red part is linked to 50 Shore A rubber properties, the orange one to 54 Shore A, and the green one to 60 Shore A.

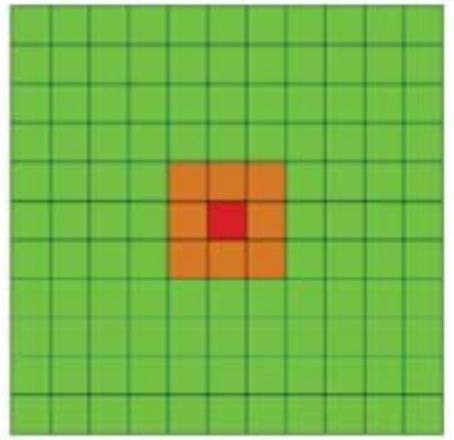

a)

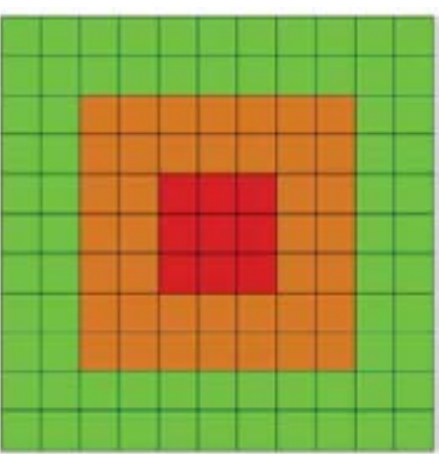

b)

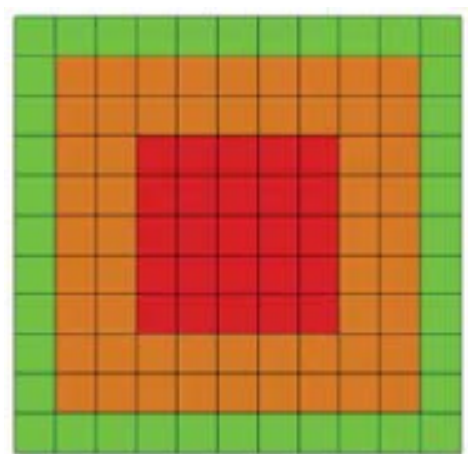

c)

Figure 6: a) external pad section, b) intermediate pad section, c) middle pad section. 


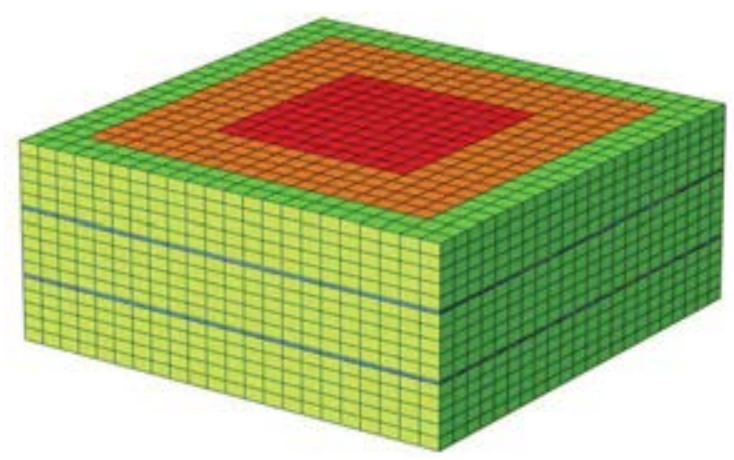

Figure 7: Middle horizontal section of FREI cured at $\mathrm{T}=130^{\circ}$.

\subsection{Results}

To compare devices' structural responses, effective horizontal stiffness $K_{H, e f f}$ and damping ratio $\xi$ have been evaluated on four cycles with maximum displacement equal to $5 \mathrm{~mm}, 15$ $\mathrm{mm}, 30 \mathrm{~mm}$ and $50 \mathrm{~mm}$ respectively. The computations are based on the equations (1)-(4):

$$
\begin{gathered}
K_{H, e f f}=\left(F_{\max }-F_{\min }\right) /\left(\Delta_{\max }-\Delta_{\min }\right) \\
\xi=W_{d} /\left(4 \Pi W_{s}\right) \\
W S=(1 / 2)^{*} K_{H, e f f}{ }^{2} \Delta^{2} \text { max }, \text { ave } \\
\Delta_{\text {max }, \text { ave }}=\left(\Delta_{\max }+\Delta_{\min }\right) / 2
\end{gathered}
$$

\begin{tabular}{|c|c|c|c|c|}
\hline Cycle & $\begin{array}{l}\text { Effective horizontal } \\
\text { stiffness } \mathbf{K}_{\mathbf{H}, \mathbf{e f f}}[\mathrm{N} \mathrm{mm}]\end{array}$ & $\begin{array}{l}\text { Damping ratio } \xi \\
{[\%]}\end{array}$ & $\begin{array}{l}\text { Effective horizontal } \\
\text { stiffness } \mathbf{K}_{\mathbf{H}, \mathbf{e f f}}[\mathrm{N} \mathrm{mm}]\end{array}$ & $\begin{array}{l}\text { Damping ratio } \xi \\
{[\%]}\end{array}$ \\
\hline & \multicolumn{2}{|c|}{ Device cured at $130^{\circ}$ for 40 minutes } & \multicolumn{2}{|c|}{ Device cured at $150^{\circ}$ for 40 minutes } \\
\hline $1^{\circ}$ & 67.59 & 6.38 & 87.65 & 7.86 \\
\hline $2^{\circ}$ & 64.86 & 5.67 & 82.41 & 7.68 \\
\hline $3^{\circ}$ & 50.30 & 7.73 & 65.34 & 10.01 \\
\hline $4^{\circ}$ & 35.08 & 11.20 & 46.20 & 13.92 \\
\hline
\end{tabular}

Table 1: Damping ratio and Effective horizontal stiffness for each cycle on the device cured at $130^{\circ}$ for 40 minutes and at $150^{\circ}$ for 40 minutes.

In Figure 8, the lateral force-displacement curves for the device cured at $130^{\circ}$ and at $150^{\circ}$ for 40 minutes are compared. In both cases, the effective horizontal stiffness decreases, passing from first to last cycle. This is a typical feature of unbonded application: the device experiences a rollover (Figure 9) which causes a nonlinear behavior, resulting in a softening behavior. Another remarkable feature appreciable in both the devices is the variation of damping ratio with the increase of lateral displacement.

The results summarized in Table 1 show how the device cured at $130^{\circ}$ is characterized by lower effective horizontal stiffness compared to the one cured at $150^{\circ}$. The same holds for the damping ratio. 


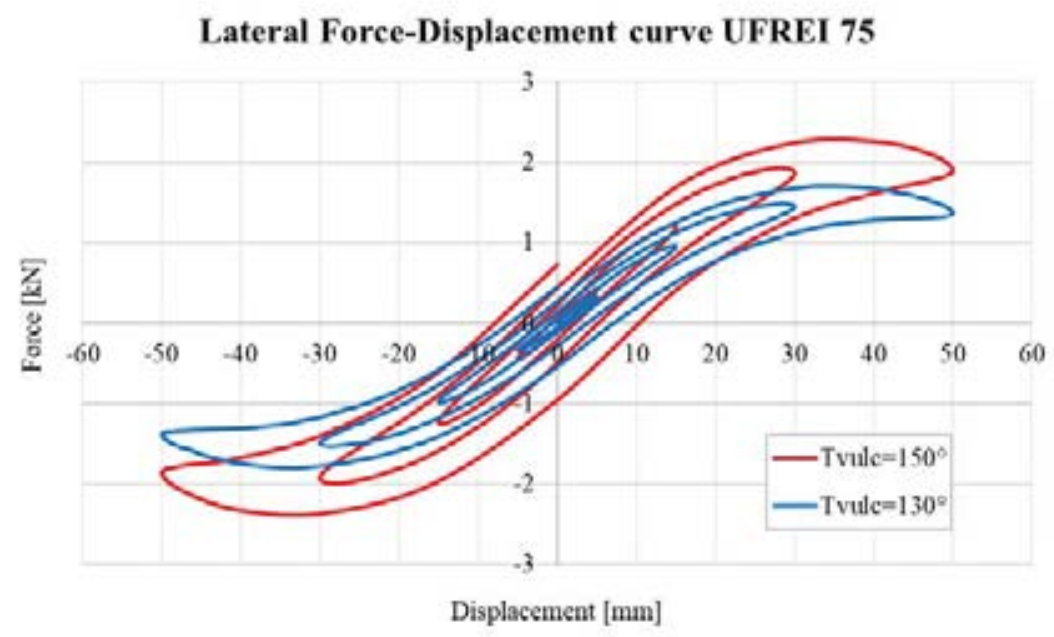

Figure 8: Lateral force-displacement curve for the unbonded FREI cured at $130^{\circ}$ for 40 minutes (blue curve) and cured at $150^{\circ}$ for 40 minutes (red curve).

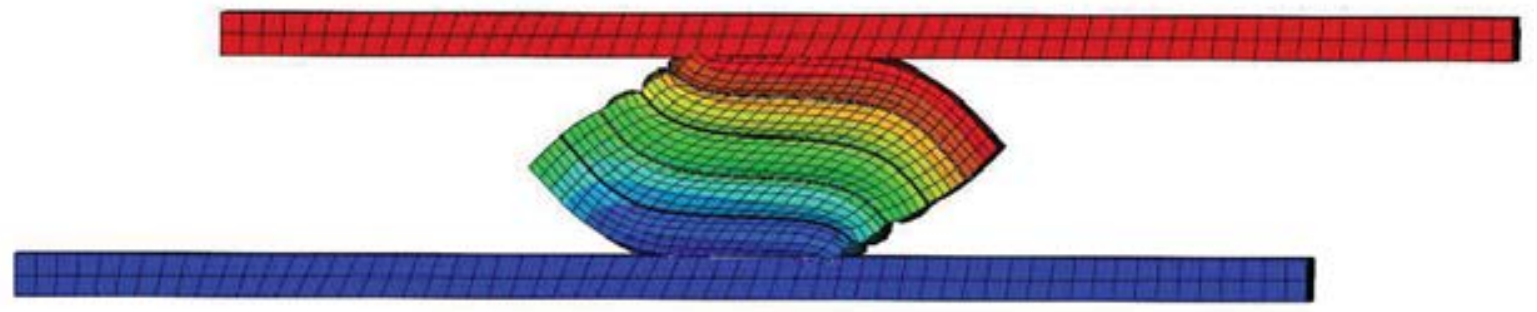

Figure 9: Typical rollover deformation due to unbonding, which causes a softening behavior

\section{CONCLUSIONS}

In this paper, the seismic performance of under-vulcanized Unbonded Fiber Reinforced Elastomeric Isolators has been studied, and it has been compared with a well-vulcanized one.

Firstly, to investigate the distribution of curing level of the under-vulcanized device, the Shore A hardness has been measured with a digital Shore A durometer along two sections. Results have shown the non-homogeneous hardness distribution and the non-homogeneous rubber mechanical properties within the base isolator.

Subsequentially, the device has been modeled through the FE software code Abaqus and cyclic shear tests have been performed, with a maximum displacement of $50 \mathrm{~mm}$. Two different seismic performances of the under-vulcanized UFREI and the well-vulcanized one have been obtained. The device cured at $130^{\circ}$ is characterized by lower effective horizontal stiffness and lower damping ratio than the one cured at $150^{\circ}$.

In conclusion, although the devices show different behavior in these cyclic shear tests, both are suitable to isolate low-rise buildings properly.

\section{REFERENCES}

[1] A. B. Habieb, M. Valente, G. Milani, Base seismic isolation of a historical church using fiber reinforced elastomeric isolators. Soil Dynamics and Earthquake Engineering, Vol. 120, 127-145, 2019. 
[2] A. B. Habieb, M. Valente, G. Milani, Hybrid seismic base isolation of a historical masonry church using unbonded fiber reinforced elastomeric isolators and shape memory alloy wires. Engineering Structures, 196, \#109281, 2019

[3] A. B. Habieb, G. Milani, T. Tavio, Two-step advanced numerical approach for the design of low-cost unbonded fiber reinforced elastomeric seismic isolation systems in new masonry buildings. Engineering Failure Analysis, 90, 380-396, 2018.

[4] H. Toopchi-Nezhad, J. Tait M., G. Drysdale R., Lateral response evaluation of fiberreinforced neoprene seismic utilized in an unbonded application. Journal of Structural Engineering, Vol. 134(10), 1627-1637, 2008.

[5] G. Russo, M. Pauletta, Sliding instability of fiber-reinforced elastomeric isolators in unbonded applications. Engineering Structures, Vol. 48, 70-80, 2013.

[6] N. C. Van Engelen, P. M. Osgooei, M. J. Tait, D. Konstantinidis, Partially bonded fiberreinforced elastomeric isolators (PB-FREIs). Structural Control and Health Monitoring, Vol. 22(3), 417-432, 2015.

[7] G. Milani, F. Milani, Optimal vulcanization of tires: Experimentation on idealized NRPB natural and poly-butadiene rubber blends, phenomenological smoothed numerical kinetic model and FE implementation, Polymer Testing, 72, 63-85, 2018.

[8] A. B. Habieb, G. Milani, F. Milani, R. Cerchiaro, Rubber compounds made of reactivated EPDM for fiber-reinforced elastomeric isolators: an experimental study. Iranian Polymer Journal, 2020.

[9] A. B. Habieb, G. Milani, R. Cerchiaro, V. Quaglini, F. Milani, Numerical study on rubber compounds made of reactivated ethylene propylene diene monomer for fiber reinforced elastomeric isolators, Polymer Engineering and Science, 2020.

[10] A. B. Habieb, G. Milani, V. Quaglini, F. Milani, Experimentation and numerical modelling of recycled rubber pads for seismic isolation under accelerated ageing. AIP Conference Proceedings, 2116, \# 420006, 2019.

[11] G. Pianese, G. Milani, R. Cerchiaro, F. Milani, Optimal Vulcanization of Unbonded Fiber Reinforced Elastomeric Isolator Devices, Chemical Engineering Transactions, Vol. 86, 2021. 